ARTICLE

DOI: $10.1038 / s 41467-017-02053-7$

\title{
Oxidative rearrangement of (+)-sesamin by CYP92B14 co-generates twin dietary lignans in sesame
}

Jun Murata (10 ${ }^{1}$, Eiichiro Ono², Seigo Yoroizuka ${ }^{3}$, Hiromi Toyonaga ${ }^{2}$, Akira Shiraishi ${ }^{1}$, Shoko Mori ${ }^{1}$, Masayuki Tera', Toshiaki Azuma1, Atsushi J. Nagano4,5, Masaru Nakayasu6 ${ }^{6}$, Masaharu Mizutani ${ }^{6}$, Tatsuya Wakasugi ${ }^{3}$, Masayuki P. Yamamoto ${ }^{3} \&$ Manabu Horikawa (D) ${ }^{1}$

(+)-Sesamin, (+)-sesamolin, and (+)-sesaminol glucosides are phenylpropanoid-derived specialized metabolites called lignans, and are rich in sesame (Sesamum indicum) seed. Despite their renowned anti-oxidative and health-promoting properties, the biosynthesis of $(+)$-sesamolin and (+)-sesaminol remained largely elusive. Here we show that (+)-sesamolin deficiency in sesame is genetically associated with the deletion of four C-terminal amino acids (Del4C) in a P450 enzyme CYP92B14 that constitutes a novel clade separate from sesamin synthase CYP81Q1. Recombinant CYP92B14 converts (+)-sesamin to (+)-sesamolin and, unexpectedly, (+)-sesaminol through an oxygenation scheme designated as oxidative rearrangement of $\alpha$-oxy-substituted aryl groups (ORA). Intriguingly, CYP92B14 also generates (+)-sesaminol through direct oxygenation of the aromatic ring. The activity of CYP92B14 is enhanced when co-expressed with CYP81Q1, implying functional coordination of CYP81Q1 with CYP92B14. The discovery of CYP92B14 not only uncovers the last steps in sesame lignan biosynthesis but highlights the remarkable catalytic plasticity of P450s that contributes to metabolic diversity in nature.

\footnotetext{
${ }^{1}$ Bioorganic Research Institute, Suntory Foundation for Life Sciences (SUNBOR), 8-1-1 Seikadai, Seika, Soraku, Kyoto 619-0284, Japan. ${ }^{2}$ Research Institute, Suntory Global Innovation Center Ltd (SIC), 8-1-1 Seikadai, Seika, Soraku, Kyoto 619-0284, Japan. ${ }^{3}$ Graduate School of Science and Engineering, University of Toyama, 3190 Gofuku, Toyama 930-8555, Japan. ${ }^{4}$ Faculty of Agriculture, Ryukoku University, 1-5 Yokotani, Seta Oe, Otsu, Shiga 520-2914, Japan. ${ }^{5}$ JST CREST, 4-1-8 Honcho, Kawaguchi, Saitama 332-0012, Japan. ${ }^{6}$ Graduate School of Agricultural Science, Kobe University, Kobe 657-8501, Japan. Jun Murata, Eiichiro Ono, and Seigo Yoroizuka contributed equally to this work. Correspondence and requests for materials should be addressed to M.P.Y. (email: mpyama@sci.u-toyama.ac.jp) or to M.H. (email: horikawa@sunbor.or.jp)
} 
S esame (Sesamum indicum) has been cultivated since antiquity and charred sesame was found in a stratum dated at between 3050 and 3500 B.C. at an Indus Valley Civilization site $^{1}$. Sesame seed oil is a rich source of unsaturated fatty acids, as well as lignans, which are phenylpropanoid-derived plant specialized metabolites chemically defined as monolignol dimers ${ }^{2,3}$. $(+)$-Sesamin, (+)-sesamolin and (+)-sesaminol glucosides are the major lignans in sesame seed, and have attracted attention for their health-promoting activities. For example, (+)-sesamin is a phytoestrogen, a precursor of the mammalian lignans enterolactone and enterodiol, and exhibits protective activity against breast and prostate cancers ${ }^{4}$. The long-term consumption of $(+)$-sesaminol is believed to inhibit pathogenic extracellular $\beta$ amyloid aggregation associated with Alzheimer disease ${ }^{5}$. Moreover, sesamol, a sesame lignan-related metabolite, has been related to photoprotective effect in UV-B irradiated lymphocytes, and repression of melanin biosynthesis by reducing cAMPdependent tyrosinase activity ${ }^{6,7}$. Lignans are often observed in the seeds of oil crops, such as olive, safflower, and flaxseed, as well as sesame, and have been implicated to be potent defense phytochemicals against microbes and other plant species ${ }^{8}$. However, in sharp contrast to the wealth of knowledge on the biological activities of lignans in mammals, the physio-ecological roles of lignans in plants remain largely elusive.

The biosynthesis of sesame lignans up to $(+)$-sesamin is well characterized. The pathway branches out from a common cascade of phenylpropanoids by stereo-selective radical coupling of two molecules of a monolignol, coniferyl alcohol, guided by a dirigent protein ${ }^{9}$. This coupling reaction results in the formation of the (+)-enantiomer of pinoresinol, a central precursor of lignans.
$(+)$-Pinoresinol is then converted to $(+)$-sesamin via sequential oxygenation resulting in the formation of two methylenedioxy bridges. This reaction is catalyzed by a single cytochrome P450 monooxygenase CYP81Q1, also known as piperitol/sesamin synthase ${ }^{10}$. In contrast, the terminal metabolism of sesame lignans, particularly (+)-sesamolin and (+)-sesaminol, remain enigmatic, with neither the type of oxygenation nor the putative substrate being well understood (Fig. 1a). This is primarily because (+)-sesamolin biosynthesis requires an atypical oxygen insertion between the furan and aromatic rings. This reaction has been rarely observed other than Justicia simplex and Phryma leptostachya ${ }^{11,12}$. Through genetic, genomic and biochemical approaches, here we identify a P450 monooxygenase CYP92B14 as the enzyme that is responsible for the oxygenation of $(+)$-sesamin to form (+)-sesamolin and (+)-sesaminol. Furthermore, the labeling experiments using stable isotopes indicate that the oxygenation involves a novel reaction scheme designated as oxidative rearrangement of $\alpha$-oxy-substituted aryl groups (ORA). The identification of CYP92B14 completes the biosynthesis of major lignans in sesame, and provides insights into yet to be characterized mechanisms of enzymatic oxygenation in specialized metabolites that possess heteroatoms at the $\alpha$-position of alkyl-substituted aryl groups.

\section{Results}

Genetic analysis of sesamolin-deficient accession \#4294. In order to identify enzyme genes responsible for the biosynthesis of $(+)$-sesamolin, recombinant inbred lines (RILs; F6 generation) of sesame were generated by crossing a $(+)$-sesamolin-deficient accession \#4294 and a (+)-sesamolin-accumulating cultivar

a<smiles>OC/C=C/c1ccc(O)c(OCO)c1</smiles>

b
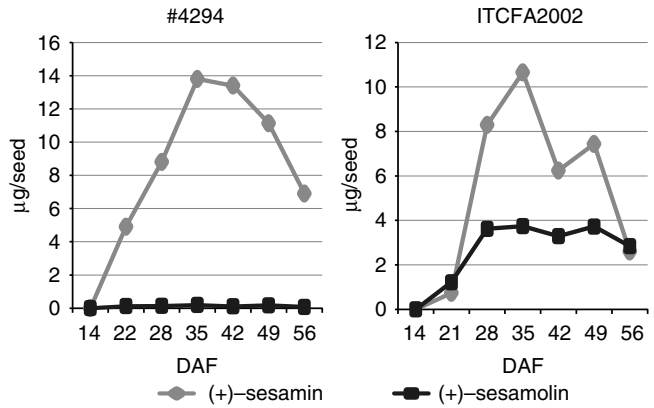

C

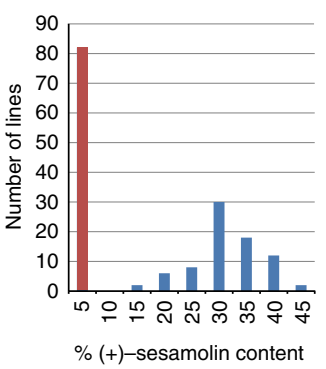

d
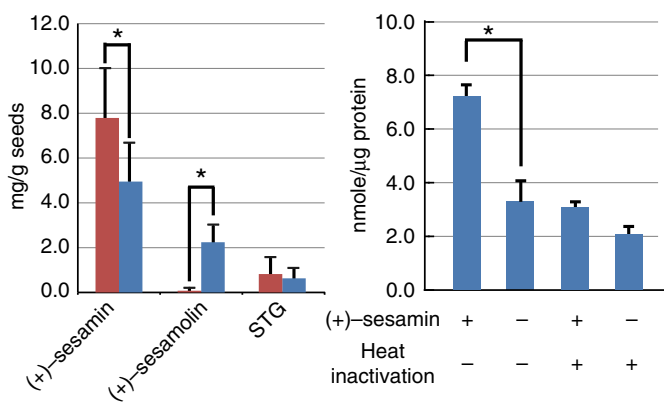

- (+)-sesamolin-deficient RILs

- (+)-sesamolin-accumulating RILs

Fig. 1 Biosynthesis of $(+)$-sesamolin. a Putative biosynthetic pathway of $(+)$-sesamolin. Ox: oxidant, Dir: dirigent protein, dashed gray arrows; reactions catalyzed in this study. b The amounts of (+)-sesamin and (+)-sesamolin in the sesame lines ITCFA2002 and \#4294 during seed development. DAF; days after flowering. c The number of individual RILs (F6) generated by crossing \#4294 and ITCFA2002 was plotted against (+)-sesamolin (\%) relative to the total lignan content. red; RILs accumulating less than 5\% (+)-sesamolin, blue; RILs accumulating 15-45\% (+)-sesamolin. d Amounts (mg/g tissue) of $(+)$-sesamin, (+)-sesamolin and (+)-sesaminol triglucoside (STG) in mature seeds from (+)-sesamolin-deficient (red) and (+)-sesamolin-accumulating (blue) RILs. Values are mean \pm SD. ${ }^{\star} P<0.05$, Mann-Whitney $U$-test, two-tailed. e (+)-sesamolin biosynthetic activity of the microsome fraction from sesame seeds. The enzyme assays were conducted with or without (+)-sesamin. Heat inactivation: incubation of the microsome fraction at $96{ }^{\circ} \mathrm{C}$ for 5 min prior to the assay. Values are mean $\pm \mathrm{SE}(n=3) .{ }^{\star} P<0.01$, Student's $t$-test 
a

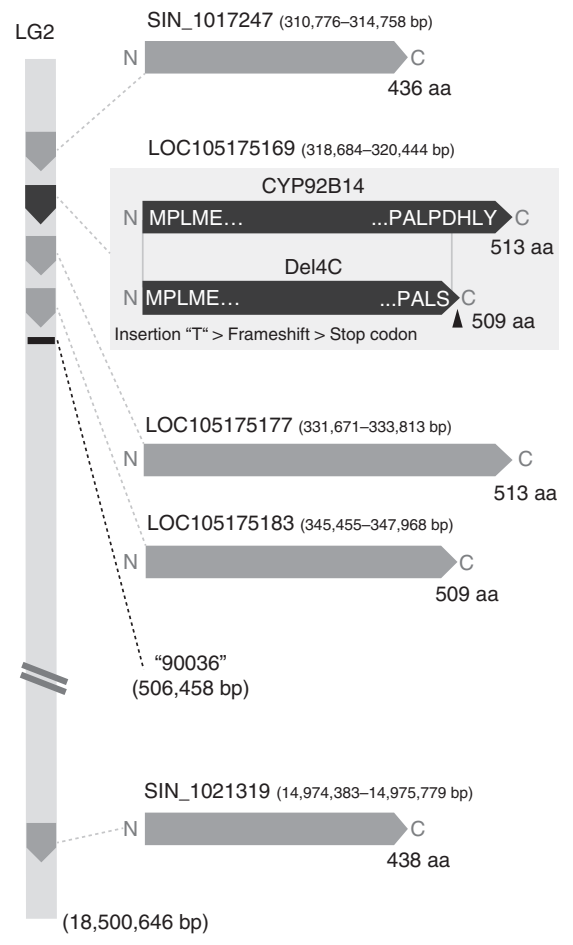

b

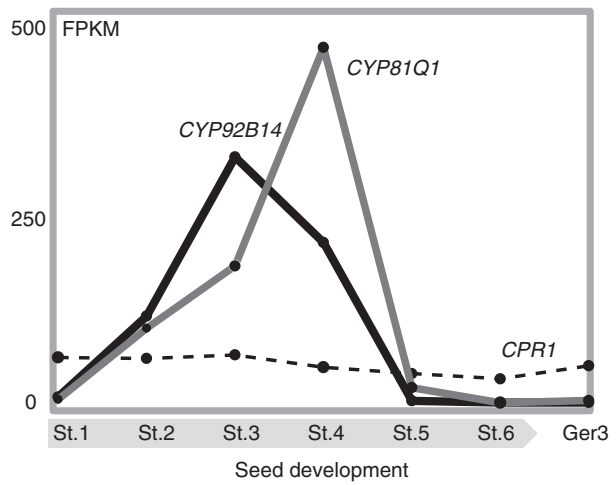

C

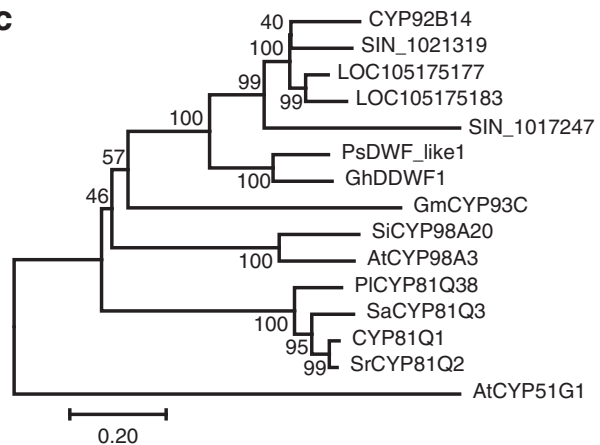

Fig. 2 Genomic structure and expression of CYP92B14. a CYP92B14, LOC105175177, LOC105175183, and SIN_1017247 are the four P450s that constitute a gene cluster in LG2. SIN_1021319 is an additional P450 similar to CYP92B14. The arrowhead indicates the position of the single-nucleotide insertion. b Gene expression analysis obtained by RNA-Seq. FPKM; fragments per Kilobase Megareads. St.; seed maturation stage ${ }^{10}$. Ger3; 3 days after germination. c Phylogenetics of CYP92B14 determined by the neighbor-joining method using MEGA7. Bootstrap values (1000 replicates) are shown next to the branches. Scale bar represents the rate of substitution/site

a

CYP92B14 + CPR 1 Del4C
+ CPR1
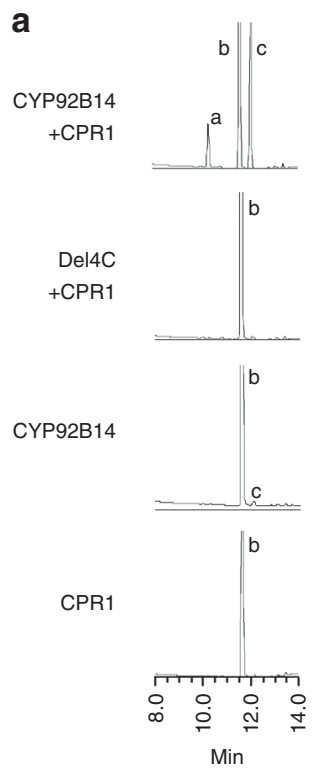

Del4C
+ CPR1
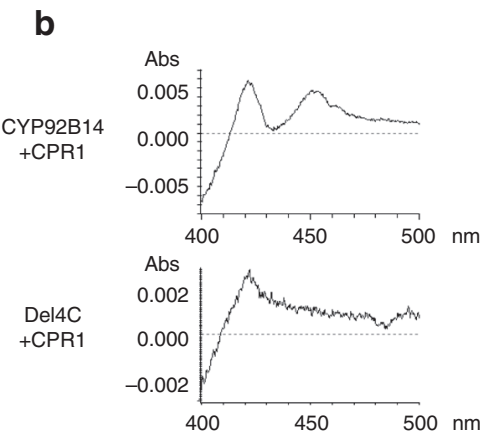

C

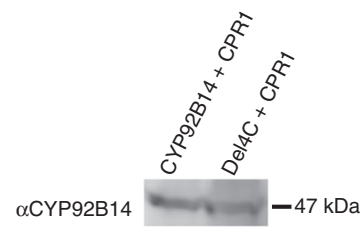

Fig. 3 CYP92B14 biosynthesizes (+)-sesamolin and (+)-sesaminol from $(+)$-sesamin in vitro. a Microsome fractions prepared from a series of transformed yeasts were subjected to enzyme assays using $(+)$-sesamin as a substrate. a: (+)-sesaminol; b: (+)-sesamin; c: (+)-sesamolin. b COdifference spectra of microsome fractions expressing CYP92B14. c Expression of recombinant CYP92B14 proteins in yeasts was immunologically detected with an anti-CYP92B14 antibody raised against the peptide sequence that is common to full-length CYP92B14 and Del4C

ITCFA2002 (Fig. 1b, Supplementary Table 1). The genetic analysis indicated that $(+)$-sesamolin was derived from $(+)$-sesamin, since (+)-sesamolin-deficient RILs accumulated increased amounts of $(+)$-sesamin compared to $(+)$-sesamolin-accumulating RILs (Fig. 1c, d). This notion was further supported by the higher level of $(+)$-sesamin in an another $(+)$-sesamolin-deficient cultivar Maruemon compared to its relative cultivars, Gomazou and Maruhime, both of which accumulate $(+)$-sesamolin ${ }^{13}$. The RILs were clearly grouped into two classes in a 1:1 ratio according to the level of $(+)$-sesamolin: of 160 lines, the relative content of $(+)$-sesamolin compared to total lignan was $<5 \%$ in 81 lines but $15-45 \%$ in 79 lines (Fig. 1d, Supplementary Table 2). Moreover, the microsome fraction of the $(+)$-sesamolin-accumulating cultivar 'Masekin' exhibited biosynthetic activity of (+)-sesamolin from $(+)$-sesamin, but the activity in the fraction was abolished by heat inactivation prior to the assay (Fig. 1e). These collectively indicate that a single genetic locus encoding a microsomal enzyme is involved in the biosynthesis of $(+)$-sesamolin.

CYP92B14 is responsible for (+)-sesamolin biosynthesis. Restriction Site Associated DNA Sequence (RAD-Seq) analysis ${ }^{14}$ of the segregated RIL lines and genetic mapping using 566 singlenucleotide polymorphism (SNP) markers covering over $90 \%$ of the RILs indicated that a marker, \#90036, on a genomic contig, linkage group $2(\mathrm{LG} 2)^{15}$, was associated with (+)-sesamolin deficiency (Fig. 2a). There was a P450 gene cluster in the corresponding genomic region, where the open reading frame (ORF) of LOC105175169, designated as CYP92B14 by P450 monooxygenase nomenclature $^{16}$, harbored a thymine insertion shared in \#4294 and Maruemon, generating a mutant lacking the four 


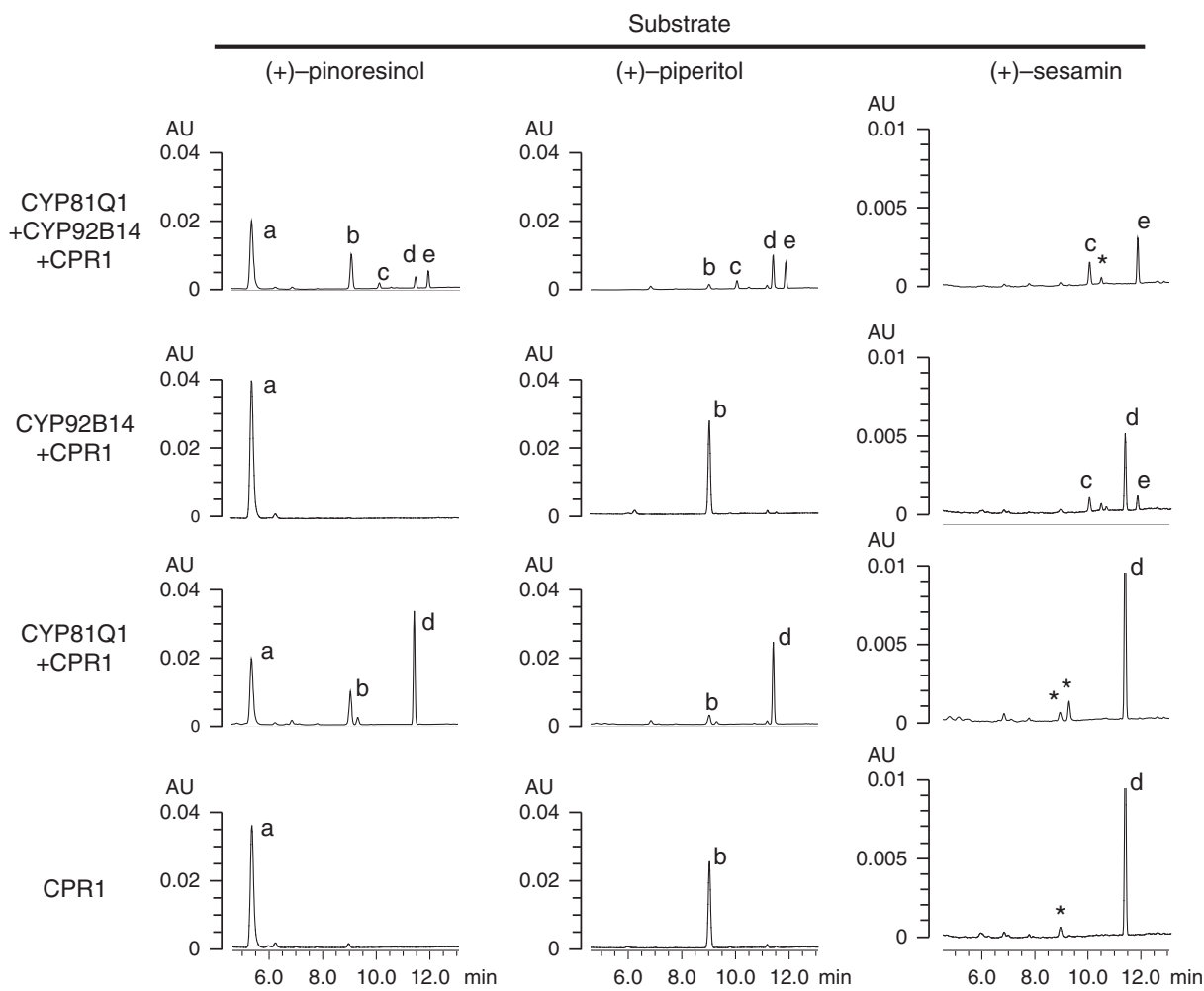

Fig. 4 Co-expression of CYP81Q1 ameliorates the activity of CYP92B14 to produce (+)-sesamolin and (+)-sesaminol from (+)-sesamin in yeast cells. Yeast cell lines expressing either or both CYP81Q1 and CYP92B14 together with CPR1 were subjected to bioassays using designated lignan as a substrate. Assay products after $48 \mathrm{~h}$ incubation were analyzed by HPLC at $283 \mathrm{~nm}$. a: (+)-pinoresinol, b: (+)-piperitol, c: (+)-sesaminol, d: (+)-sesamin, e: (+)-sesamolin. Asterisks indicate unknown peaks

C-terminal amino acids (Del4C) (Fig. 2c, Supplementary Fig. 1). The expression of CYP92B14 was increased during the mid-stage of seed development (Fig. 2b, Supplementary Figs. 2, 3). This profile coincided with that of sesamin synthase CYP81Q1 (Fig. 1a) ${ }^{10}$, and proceeded to the accumulation of $(+)$-sesamolin. In contrast, $S$. indicum cytochrome P450 oxidoreductase 1 (CPR1) was expressed throughout seed development. The expression level of CYP92B14 was considerably higher than that of any other CYP gene except LOC105175177 (Supplementary Fig. 3). CYP92B14 and four other P450s identified in LG2 were grouped into the CYP92 family, which is widely found in gymnosperms and angiosperms. These five P450s are phylogenetically close to PsDWF_like ${ }^{17}$, which is involved in brassinosteroid biosynthesis, but distant from two phenylpropanoid-related P450s, coumarate 3-hydroxylase (C3H; CYP98A20) and CYP81Q1 (Fig. 2a, c, Supplementary Fig. 4).

Biochemical characterization of CYP92B14. Biochemical analysis showed that the microsome fraction from yeast cells expressing CYP92B14 and CPR1 converted (+)-sesamin to (+)-sesamolin (Fig. 3a). Furthermore, co-existence of CPR1 with CYP92B14 substantially enhanced the catalysis. Conversely, Del4C lost the ability to biosynthesize (+)-sesamolin (Fig. 3a). CO-difference spectrum analysis indicated that Del4C was expressed as an inactive form as shown by the absence of a peak at $450 \mathrm{~nm}$ (Fig. 3b), while its expression level in yeast was comparable to that of CYP92B14 (Fig. 3c, Supplementary Fig. 5). Moreover, Del4C in mature seeds of the $(+)$-sesamolin-deficient RIL (\#119) was expressed at a level comparable to that of CYP92B14 in the (+)-sesamolin-accumulating RIL (\#89) (Supplementary Fig. 6). On the other hand, introduction of the amino acid substitution P509S to CYP92B14 did not result in the loss of the catalytic activity (Supplementary Fig. 7). These data indicate that functional impairment originated from the lack of four amino acids in the C-terminus of CYP92B14, but not the lack of CYP92B14 expression, is responsible for (+)-sesamolin deficiency in \#4294. Intriguingly, CYP92B14 also generated (+)-sesaminol from (+)-sesamin, whereas Del4C lacked such activity (Fig. 3a), showing that CYP92B14 is a multifunctional enzyme that cogenerates $(+)$-sesamolin and $(+)$-sesaminol.

Effects of co-expression of CYP81Q1 on CYP92B14. Various plant P450 enzymes have been implicated to interact and form complexes called metabolon with enzymes that catalyze sequential reactions in a metabolic pathway ${ }^{18}$. To assess whether CYP81Q1 affects the catalytic activity of CYP92B14, CYP81Q1 was expressed in yeast cells together with CYP92B14 and CPR1, and was subjected to the bioassays. Yeast cells co-expressing CYP81Q1, CYP92B14, and CPR1 converted (+)-pinoresinol to $(+)$-sesaminol and $(+)$-sesamolin via $(+)$-sesamin, demonstrating sequential lignan biosynthesis by the distinct P450s (Fig. 4). Notably, when $(+)$-sesamin was supplied as a substrate, yeast cells harboring CYP81Q1, CYP92B14, and CPR1 produced increased amount of $(+)$-sesaminol and $(+)$-sesamolin compared to those expressing CYP92B14 and CPR1 but without CYP81Q1 (Fig. 4, Supplementary Fig. 7). Furthermore, while (+)-sesamin supplied as the substrate was detectable in yeast cells expressing CYP92B14 and $C P R 1$, it was completely consumed in yeast cells expressing CYP92B14 and CYP81Q1 together with CPR1. On the other hand, CYP81Q1 alone did not react with (+)-sesamin, and CYP92B14 alone showed no apparent catalytic activity toward (+)-pinoresinol and (+)-piperitol. These data suggest catalytic cooperation between CYP81Q1 and CYP92B14 for biosynthesis of (+)-sesamolin and (+)-sesaminol. 
CYP92B14 mediates unique oxygenation schemes. The oxygenation scheme by CYP92B14 was expected to be unique, since CYP92B14 co-generated twin products, $(+)$-sesaminol and $(+)$-sesamolin, from a single substrate $(+)$-sesamin. CYP92B14 incorporated oxygen from molecular oxygen, but not $\mathrm{H}_{2} \mathrm{O}$, for the oxygenation catalysis as with other P450s (Supplementary Fig. 8). NMR analysis of CYP92B14 assay products showed that the deuterium-labeling content in $(+)$-sesaminol and

a

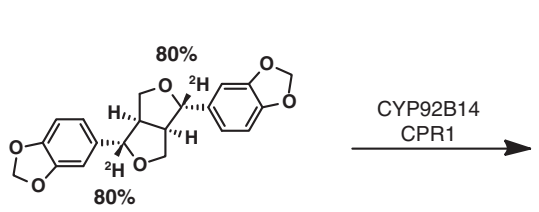

$(+)-7,7^{\prime}-{ }^{2} \mathrm{H}_{2}$-sesamin
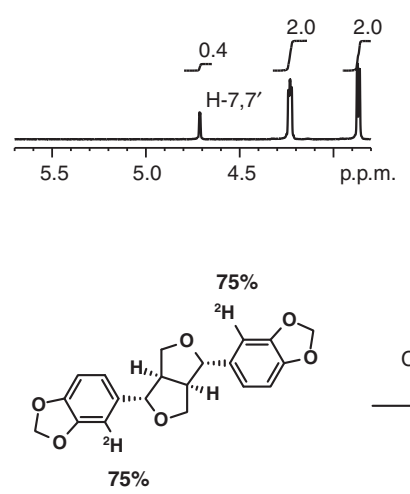

(+)-2, $2^{\prime}-{ }^{2} \mathrm{H}_{2}$-sesamin

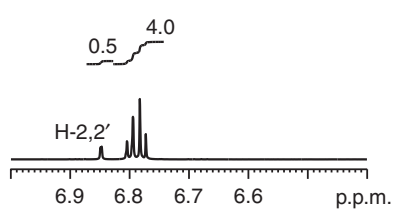

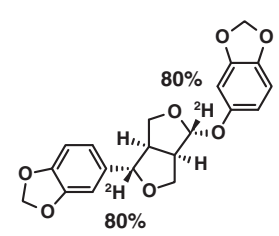

$(+)-7,7^{\prime}-2 \mathrm{H}_{2}$-sesamolin
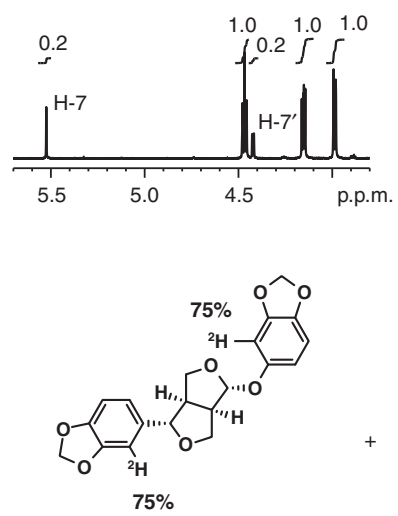

(+)-2, $2^{\prime}-{ }^{2} \mathrm{H}_{2}$-sesamolin

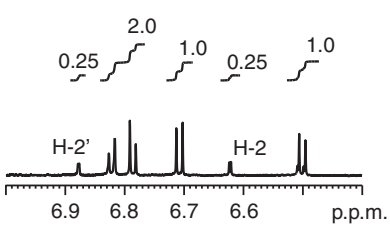

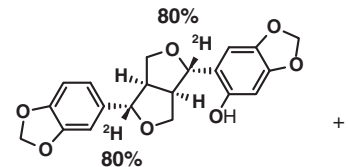

$(+)-7,7^{\prime}-{ }^{2} \mathrm{H}_{2}$-sesamin

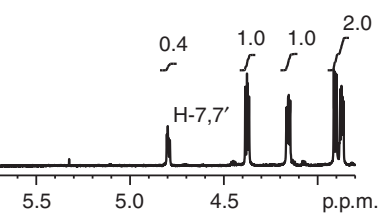

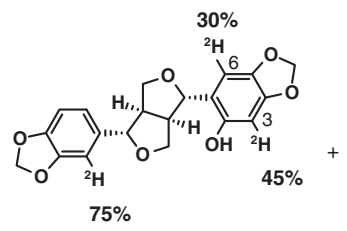

(+)-(3 or 6$), 2^{\prime}-{ }^{2} \mathrm{H}_{2}$-sesaminol

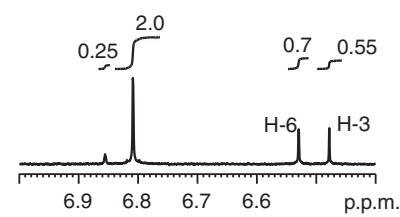

b

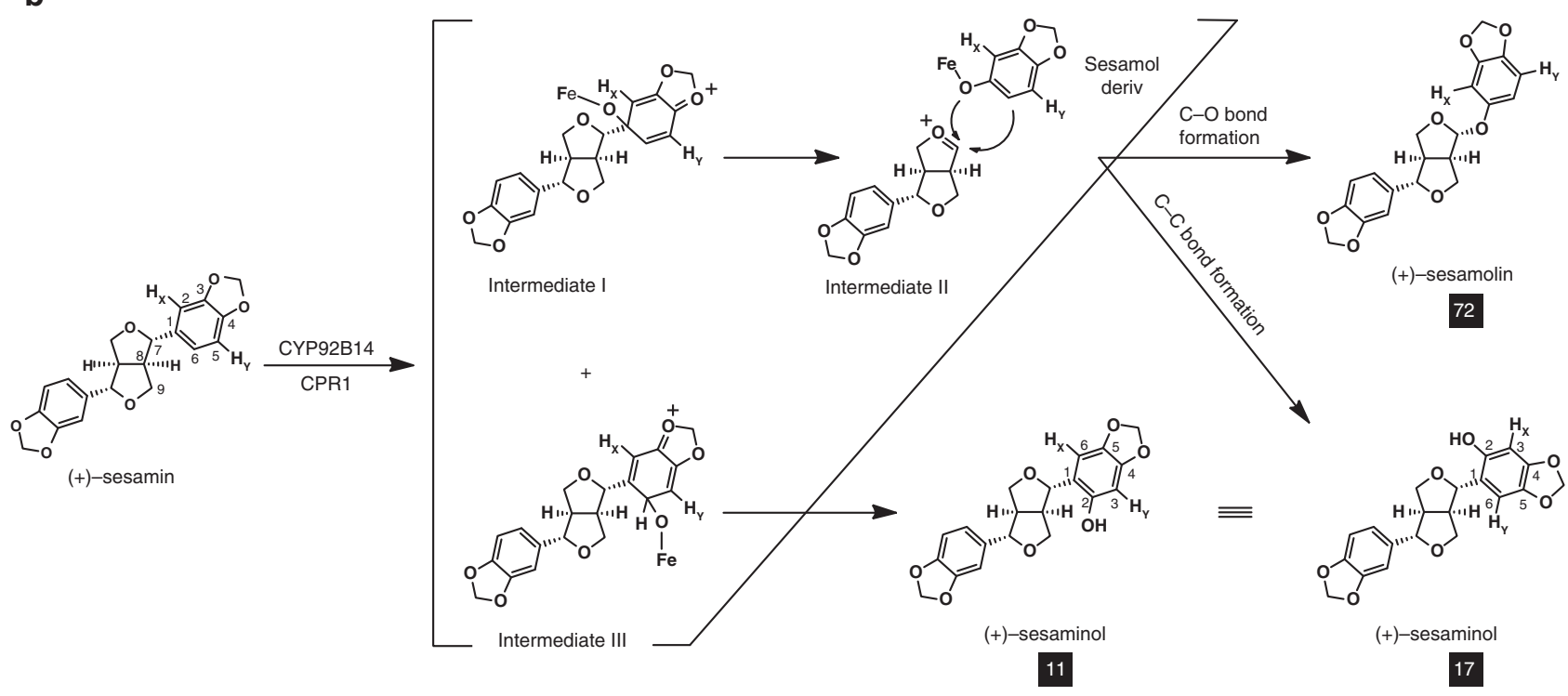

Fig. 5 CYP92B14 generates (+)-sesamolin and (+)-sesaminol from (+)-sesamin through multiple oxygenation schemes. a Enzyme assays using deuterated $(+)$-sesamin revealed the sites of initial oxidation by CYP92B14. No differences in the positions and deuterium-labeling content in $(+)-7,7^{\prime}-{ }^{2} \mathrm{H}_{2}$-sesamin and $(+)-2,2^{\prime}-{ }^{2} \mathrm{H}_{2}$-sesamin were observed between before and after the reaction. Values (\%) represent deuterium-labeling content calculated from NMR data. Note that the C3 and C6 positions of (+)-sesaminol correspond to the C5 and C2 positions of (+)-sesamin, respectively. b Proposed reaction pathways from $(+)$-sesamin to $(+)$-sesamolin and $(+)$-sesaminol. White letters indicate the molar ratio of respective enzyme assay products deduced from NMR analysis. The total amount of produced $(+)$-sesamolin and $(+)$-sesaminol was set as 100 
$(+)$-sesamolin was essentially identical to that in the substrate (+) $-7,7^{\prime}-{ }^{2} \mathrm{H}_{2}$-sesamin $\left(80 \%{ }^{2} \mathrm{H}\right.$ for each position) (Compound $\mathbf{1}$ ) (Fig. 5a). Alternatively, deuterium-labeling content in (+)-sesaminol was changed in the $\mathrm{C} 3$ and $\mathrm{C} 6$ positions $\left(\mathrm{C} 3: 45 \%{ }^{2} \mathrm{H}, \mathrm{C} 6\right.$ : $\left.30 \%{ }^{2} \mathrm{H}\right)$ when $(+)-2,2{ }^{\prime}-{ }^{2} \mathrm{H}_{2}$-sesamin $\left(75 \%{ }^{2} \mathrm{H}\right.$ for each position) (Compound 2) was used as a substrate (Fig. 5a). The deuteriumlabeling content at the $\mathrm{C} 2$ or $\mathrm{C} 2{ }^{\prime}$ positions of $(+)$-sesamolin was unchanged from that of the substrate $(+)-2,2^{\prime}-{ }^{2} \mathrm{H}_{2}$-sesamin. These results show that, for the biosynthesis of $(+)$-sesamolin, CYP92B14 catalyzes $\mathrm{C}-\mathrm{O}$ bond formation between the intermediate II and sesamol via intermediate I following the initial oxidation of (+)-sesamin at $\mathrm{Cl}$ position and the continuous cleavage of the furan and aromatic rings (Fig. 5b), which is comparable to that of $\mathrm{P} 450$-dependent $\mathrm{C}-\mathrm{C}$ bond cleavage of $p$ hydroxybenzyl alcohol ${ }^{19}$. On the other hand, CYP92B14 biosynthesizes (+)-sesaminol by two separate pathways: (i) C-C bond formation between the intermediate II and sesamol as in the case of sesamolin biosynthesis, and (ii) direct oxygenation of the aromatic ring via intermediate III following the initial oxidation of $(+)$-sesamin at the C6 position (Fig. 5b). These oxygenation positions catalyzed by CYP92B14 for $(+)$-sesamolin and $(+)$-sesaminol biosynthesis were clearly distinct from that of $(+)$-episesaminone, which is tautomerically generated by oxygenation at the $\mathrm{C} 7$ position through hemiacetal intermediate ${ }^{3,20}$. NMR analysis of CYP92B14 assay products using $(+)-2,2^{\prime}{ }^{2}{ }^{2} \mathrm{H}_{2}-$ sesamin and $(+)-7,7^{\prime}-{ }^{2} \mathrm{H}_{2}$-sesamin also showed that CYP92B14mediated catalysis yielded (+)-sesamolin through ORA, $(+)$-sesaminol through ORA and (+)-sesaminol through direct oxygenation in a molar ratio of 72:17:11, respectively, (Fig. 5b).

\section{Discussion}

CYP92B14 catalyzed the intricate reactions; a novel oxygenation designated as ORA and a well-characterized direct oxygenation of aromatic ring. ORA involved (i) the oxygenation of carbon atom on the aromatic ring system substituted with alkyl group, possibly via cation intermediate, (ii) the cleavage of the $\mathrm{C}-\mathrm{C}$ bond between the aromatic and $\alpha$-oxy-substituted alkyl groups, followed by (iii) the addition of the generated phenol adduct and the oxonium intermediate (Fig. 5b). Enzyme assays using deuterated $(+)$-sesamin clearly indicated that CYP92B14 catalyzed the oxidation of aromatic ring of (+)-sesamin. P450 monooxygenases in general operate the initial oxidation of a phenolic substrate through electrophilic attack of $\mathrm{FeO}$ complex to the aromatic ring, which generates a cation rather than radical intermediate ${ }^{21}$. Therefore, CYP92B14 likely generates cation intermediates I and III in the initial oxidation of $(+)$-sesamin. The preference of the generation of intermediate I over intermediate III, and that of $\mathrm{C}-\mathrm{O}$ over $\mathrm{C}-\mathrm{C}$ bonding in the addition of the phenol adduct to the oxonium intermediate (Fig. 5b) would largely reflect the structural constraints of the active site. Although plant specialized metabolites rarely harbor an insertion of an oxygen atom between aromatic and $\alpha$-oxy-substituted alkyl group as in (+)-sesamolin ${ }^{11}$, the initial oxygenation step of ORA might be widespread outside sesame lignans. For example, a quinoid glycoside forsythenside $\mathrm{B}^{22}$ from Forsythia suspensa, a pretocarpan hydroxycristacarpone $^{23}$ from Erythrina orientalis and a sesquiterpene hydroxycacalolide ${ }^{24}$ from Ligularia virgaurea all possess 4 -alkyl4-hydroxy-2,5-cyclohexadienone partial structures generated by the oxidation of 4-alkylphenol compounds, respectively (Supplementary Fig. 9). Moreover, a characteristic hydroxyl group at the $\mathrm{C} 1$-position of the $\mathrm{B}$-ring in protoapigenone and protogenkwanone in the fern genera Thelypteris and Pseudophegopteris likely to be generated by oxygenation analogous to that by CYP92B14 (Supplementary Fig. 9) ${ }^{25,26}$. Furthermore, it is plausible that 5,7-dihydroxychromone accumulated in Magnifera foetida and various other plant species is derived from $\mathrm{C}-\mathrm{C}$ bond cleavage of the flavanone naringenin (Supplementary Fig. 9) ${ }^{27-32}$. Since no enzymes that catalyze these oxygenation reactions have been identified so far, CYP92B14 is the first example of enzymes that mediates the oxygenation of the carbon atom on the aromatic ring system substituted with alkyl group. It is of particular interest whether the putative $\mathrm{P} 450$ enzyme encoded by LOC105175177 exhibits any enzyme activity toward sesame lignans. However, our attempts to identify the activity of the P450 enzyme have not been successful so far, since we failed to express LOC105175177 in yeast (Supplementary Fig. 5). Future establishment of the expression system of LOC105175177 and its functional characterization in comparison to CYP92B14 may provide further insights into the molecular mechanism of ORA that is mediated by this type of P450 enzymes. ORA might also be applicable to other classes of specialized metabolites including isoquinoline alkaloids and lignin polymers, since these metabolites have $\alpha$-oxy-substituted aromatic ring as a common structural feature (Supplementary Fig. 9). In particular, typical lignin polymers contain multiple putative sites for oxygen insertion by ORA, implicating that the use of enzymes with catalytic activity similar to CYP92B14 facilitates full decomposition of lignan units that are otherwise indigestible by other classes of lignin-degrading enzymes ${ }^{33,34}$.

Although the C-terminal region of P450s is unlikely to be directly associated with the substrate-binding domain ${ }^{35}$, the Cterminal region seems to be indispensable for the catalytic activity of P450. For example, an amino acid substitution P497R in Homo sapiens CYP27B1 leads to the functional impairment and is responsible for vitamin $\mathrm{D}$-dependent rickets type $\mathrm{I}$ and cerebrotendinous xanthomatosis ${ }^{36}$. On the other hand, in the case of CYP92B14 mutant Del4C, which lacks the last four residues in its C-terminus and contains P509S substitution because of the thymine insertion, is unable to catalyze the reaction (Fig. 2a, Supplementary Fig. 1), whereas P509S mutant harboring full-length sequence remains active (Supplementary Fig. 7). Although the molecular mechanism behind the loss of oxygenation activity of these P450s is unclear, these data corroborate the implicit functional importance of the C-terminal region of $\mathrm{P} 450 \mathrm{~s}^{36}$.

Importantly, sesamol and (+)-samin, a hydrate of the oxonium intermediate, were generated when CYP92B14 was supplied with (+)-sesamin (Supplementary Fig. 10). Moreover, the supplementation of these two compounds clearly inhibited the biosynthetic activity of CYP92B14 to form (+)-sesamolin and $(+)$-sesaminol from (+)-sesamin (Supplementary Fig. 11). These results supported the notion that sesamol and intermediate II were potent reaction intermediates of $(+)$-sesamolin and (+)-sesaminol biosynthesis (Fig. 5b), and partly explained why the total amount of $(+)$-sesamolin and $(+)$-sesaminol produced was substantially smaller than the amount of $(+)$-sesamin consumed in the yeast bioassay (Fig. 4, Supplementary Fig. 10). The lack of sesamol and (+)-samin production by Del4C (Supplementary Fig. 10) $)^{37}$ indicated that Del4C was unable to cleave the inert $C-C$ bond between the furan and aromatic rings of $(+)$-sesamin.

The identification of CYP92B14 uncovered the final steps in the biosynthetic pathway of all major lignans in $S$. indicum, $(+)$-sesamin, (+)-sesaminol and (+)-sesamolin, being $(+)$-sesamin as a precursor for $(+)$-sesaminol and $(+)$-sesamolin (Supplementary Fig. 12). This was biochemically confirmed by the result that the expression of CYP81Q1, CYP92B14, and CPR1 in yeast cells was sufficient to produce $(+)$-sesaminol and $(+)$-sesamolin from (+)-pinoresinol (Fig. 4). (+)-Sesamolinol, although previously proposed to be a putative precursor for $(+)$-sesamolin biosynthesis $^{38}$, is unlikely to be directly related to the biosynthesis of $(+)$-sesamolin, since $(+)$-sesamolinol and $(+)$-piperitol were not accepted as substrates by CYP81Q1 and CYP92B14, 
respectively (Fig. 4) ${ }^{10,39}$. However, there might be additional enzymes, other than CYP92B14, that are responsible for $(+)$-sesaminol biosynthesis in $S$. indicum, since sesamolindeficient RILs accumulate (+)-sesaminol triglucoside (STG) in vivo to a level comparable to that of sesamolin-producing RILs, while Del4C does not biosynthesize (+)-sesaminol in vitro (Figs. 1d, 3a).

Co-generation of structurally different metabolites through ORA, as evidenced in this study, reveals the outstanding enzymatic plasticity of P450s to elaborate structurally diverged specialized metabolites for increased environmental fitness. CYP92B14 could have recently evolved following the establishment of (+)-sesamin biosynthesis in an ancestor of Sesamum spp., given that (i) (+)-sesamolin is a lineage-specific lignan in Sesamum spp. ${ }^{40}$, (ii) (+)-sesamin is the specific substrate for CYP92B14, and (iii) CYP81Q1 and CYP92B14 are phylogenetically distinct $\mathrm{P} 450 \mathrm{~s}$ despite the high structural similarities between their substrates/products. The capability of CYP81Q1 to ameliorate the activity of CYP92B14 (Fig. 4) further substantiated the versatility of $\mathrm{P} 450 \mathrm{~s}$ in producing multiple specialized metabolites. Enzymes that were involved in primary metabolism (i.e., glycolysis, amino acid biosynthesis and TCA cycle), as well as various specialized metabolism in plants, in particular, have been implicated to form multiple enzyme complexes that carry out sequential enzymatic reactions ${ }^{18,41}$. However, major effort has been made to detect physical association of enzymes that form metabolons, and only few examples biochemically rationalized the formation of such complexes ${ }^{18,42-44}$. Therefore, our data suggesting that the activity of CYP92B14 is functionally associated with CYP81Q1 may provide a novel system to study structure-function relationship of enzymes that function cooperatively.

Consequently, our data not only complete the biosynthesis of major lignans in sesame, but provide tools for heterologous expression of valuable dietary lignans. Furthermore, our findings open a gate for novel chemical perspective with respect to oxygenation through ORA in various classes of specialized metabolites that possess heteroatoms at the $\alpha$-position beyond sesame lignans (Supplementary Fig. 9), thus established a novel molecular basis for enlarging the structural diversity of specialized metabolites in nature.

\begin{abstract}
Methods
Plant materials. Sesamum indicum cv. Masekin plants were cultivated in a field in Osaka, Japan. Immature seeds were collected along the developmental stage index as described previously ${ }^{10}$. S. indicum cv. Maruemon was a gift from National Agriculture and Food Research Organization (NARO). S. indicum ITCFA2002 was kindly provided by T. Amano (ITOCHU) and T. Kondo (Nippon Norin Seed). F1 plants and RILs from a cross between \#4294 and ITCFA2002 were grown in a greenhouse at University of Toyama.
\end{abstract}

RAD-Seq and genetic analyses. Genomic DNA of RILs and their parental lines (\#4294 and ITCFA2002) were isolated from young leaves using the cetyl trimethylammonium bromide (CTAB) method with some modifications. Briefly, a fine frozen tissue powder was washed three times with washing buffer $(0.5 \mathrm{M}$ HEPES ( $\mathrm{pH} 8.0$ ), $0.1 \%$ polyvinylpyrrolidone, $4 \% \beta$-mercaptoethanol) and then subjected to DNA extraction by the CTAB method, but omitting the $\mathrm{CsCl}$ precipitation step. The genomic DNAs were adjusted to $50 \mathrm{ng} / \mu \mathrm{l}$ and used for RADSeq analysis as described previously ${ }^{45}$. RIL SNP was genotyped by the derived Cleaved Amplified Polymorphic Sequence (dCAPS) method ${ }^{46}$ using the primer sets 5'-GCCATCTTTGGTTTCTGGTG-3' and 5'-TGGGACTGACTCAACGGC-3' for the \#90032 marker, and restriction enzyme Hae III. PCR was performed using TAKARA Ex Taq Hot Start Version (TAKARA) DNA polymerase under the following conditions: an initial cycle at $94^{\circ} \mathrm{C}$ for $2 \mathrm{~min}, 35$ cycles at $98^{\circ} \mathrm{C}$ for $10 \mathrm{~s}, 60^{\circ}$ $\mathrm{C}$ for $30 \mathrm{~s}, 72^{\circ} \mathrm{C}$ for $30 \mathrm{~s}$, and a final extension step at $72^{\circ} \mathrm{C}$ for $2 \mathrm{~min}$. Linkage analysis of RAD markers and the $(+)$-sesamolin content trait was performed using Antmap ver. 1.2 software $^{47}$.

RT-PCR. Total RNA was extracted from developing seeds using RNeasy Plant Mini Kit (Qiagen). After DNase I (TAKARA) treatment, cDNA was synthesized from oligo dT primer using PrimeScript RT reagent Kit (TAKARA). Reactions were conducted according to manufactures' instructions. PCR was performed using primer sets (Supplementary Table 3 ) under the conditions described above. Primers for UBQ6 were designed as reported previously ${ }^{48}$.

Phylogenetic analysis. Phylogenetic analysis of CYP92B14 and 12 other P450 monooxygenases from plants was conducted using the UPGMA method with MEGA $7^{49}$. The accession numbers of the genes subjected to phylogenetic analysis are as follows; SiCYP92B14, LC199944; SiCYP98A20, NP_001291339; SiCYP81Q1, BAE48234; SrCYP81Q2, BAE48235; SaCYP81Q3, BAE48236; PICYP81Q38, BAP46307; GmCYP93C, SBU44858; AtCYP51G1, NP_172633; AtCYP98A3, OAP09214; PsDWF_like1, AAG44132; and GhDDWF1, ABA01477.

Chemicals. (+)-Pinoresinol and (+)-sesaminol (Nagara Science) were used without further purification. $(+)$-Sesamin (ChromaDex) was sequentially purified by normal, followed by reverse phase column chromatography. (+)-Sesamolin was isolated during the purification of $(+)$-sesamin. For the synthesis of $(+)$-samin, $(+)$-sesamolin was treated with $3 \mathrm{~N}$ aqueous hydrogen chloride in dioxane at $45^{\circ} \mathrm{C}$ for $1 \mathrm{~h}^{37}$. For the synthesis of $(+)$-piperitol, $(+)$-sesamin was treated with diisobutyl aluminum hydride in toluene at $140^{\circ} \mathrm{C}$ for $1 \mathrm{~h}^{39}$. Sesamol and other chemical reagents, including solvents, were purchased from Tokyo Chemical Industry, Sigma-Aldrich or Nacalai Tesque.

Chemical synthesis of stable isotope-labeled sesamin. (+)-7, $7^{\prime}-{ }^{2} \mathrm{H}_{2}$-sesamin (1): (+)-Sesamin $(270 \mathrm{mg}, 0.762 \mathrm{mmol})$ was subjected to $4.0 \mathrm{kgf} / \mathrm{cm}^{2}$ of hydrogen in the presence of $\mathrm{Pd}(\mathrm{en})(270 \mathrm{mg})$ in a mixture of 1,4-dioxane $(4.2 \mathrm{ml})$ and deuterium oxide $(1.8 \mathrm{ml})$ at $110^{\circ} \mathrm{C}$ for 3 days ${ }^{50}$. After filtration of the reaction mixture, the filtrate was purified by reverse phase column chromatography to provide deuterated 1 (153 mg, $0.429 \mathrm{mmol}, 56 \%)$. The ${ }^{2} \mathrm{H}$ content at the $\mathrm{C} 7$ and $\mathrm{C7}^{\prime}$ of deuterated $(+)$-sesamin was $80 \%$, as estimated by comparison of the hydrogen intensity of $\mathrm{H}-7,7^{\prime}$ and $\mathrm{H}-9 \mathrm{a}, 9^{\prime} \mathrm{a}$ in a ${ }^{1} \mathrm{H}$ NMR experiment.

1: $\mathrm{mp} 123-124^{\circ} \mathrm{C} ;[\alpha]_{\mathrm{D}}^{25}+67.7^{\circ}\left(\mathrm{c} 0.16, \mathrm{CHCl}_{3}\right) ;{ }^{1} \mathrm{H}$ NMR $\left(800 \mathrm{MHz}, \mathrm{CDCl}_{3}\right)$ $\delta 3.05\left(2 \mathrm{H}, \mathrm{m}, \mathrm{H}-8,8^{\prime}\right), 3.87\left(2 \mathrm{H}, \mathrm{dd}, J=2.4,9.2 \mathrm{~Hz}, \mathrm{H}-9 \mathrm{a}, 9^{\prime} \mathrm{a}\right), 4.23(2 \mathrm{H}, \mathrm{dd}, J=$ 6.6, 9.2 Hz, H-9b, 9'b), $4.71\left(2 \mathrm{H}, \mathrm{d}, J=3.5 \mathrm{~Hz}, \mathrm{H}-7,7^{\prime}\right), 5.95\left(4 \mathrm{H}, \mathrm{s}, \mathrm{H}-10,10^{\prime}\right), 6.78$ $\left(2 \mathrm{H}, \mathrm{d}, J=8.0 \mathrm{~Hz}, \mathrm{H}-5,5^{\prime}\right), 6.80\left(2 \mathrm{H}\right.$, br d, $\left.J=8.0 \mathrm{~Hz}, \mathrm{H}-6,6^{\prime}\right), 6.85(2 \mathrm{H}$, br s, H-2,

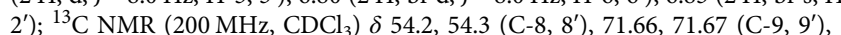
$85.4\left(\mathrm{t}, J=22.0 \mathrm{~Hz}, \mathrm{C}-7,7^{\prime}\right), 85.8\left(\mathrm{C}-7,7^{\prime}\right), 101.1\left(\mathrm{C}-10,10^{\prime}\right), 106.5\left(\mathrm{C}-2,2^{\prime}\right), 108.2$ $\left(\mathrm{C}-5,5^{\prime}\right), 119.3,119.4\left(\mathrm{C}-6,6^{\prime}\right), 134.97,135.03\left(\mathrm{C}-1,1^{\prime}\right), 147.0,147.1\left(\mathrm{C}-4,4^{\prime}\right), 148.0$ $\left(\mathrm{C}-3,3^{\prime}\right)$. HRMS (ESI): $[\mathrm{M}+\mathrm{Na}]^{+}$calculated for $\mathrm{C}_{20} \mathrm{H}_{16} \mathrm{D}_{2} \mathrm{O}_{6} \mathrm{Na}: \mathrm{m} / z$ 379.3549, found: 379.3542. NMR spectra of 1 are shown in Supplementary Figs. 13-15.

$(+)-2,2^{\prime}-{ }^{2} \mathrm{H}_{2}$-sesamin (2): Synthesis of $(+)-2,2{ }^{\prime}-{ }^{2} \mathrm{H}_{2}$-sesamin was performed basically as reported previously ${ }^{51}$. To a solution of $(+)$-sesamin $(354 \mathrm{mg}, 1.0 \mathrm{mmol})$ in dry tetrahydrofuran $(5 \mathrm{ml})$ was added $\mathrm{n}$-BuLi $(1.5 \mathrm{ml}, 1.6 \mathrm{~mol} / \mathrm{L}$ in toluene) at $-78^{\circ} \mathrm{C}$ under argon. After stirring for $30 \mathrm{~min}$, methanol- $\mathrm{d}_{4}(0.5 \mathrm{ml})$ was added, the solution was allowed to warm to room temperature, then the solution was partitioned between $\mathrm{H}_{2} \mathrm{O}$ and ethyl acetate, the organic layer washed with saturated $\mathrm{NaCl}$ solution, dried $\left(\mathrm{MgSO}_{4}\right)$ and concentrated in vacuo to dryness. The resulting residue was purified by reverse phase column chromatography to provide deuterated 2 (185 mg, $0.519 \mathrm{mmol}, 52 \%)$. The ${ }^{2} \mathrm{H}$ content at the $\mathrm{C} 2$ and $\mathrm{C} 2{ }^{\prime}$ of deuterated $(+)$-sesamin was $75 \%$, as estimated by comparison of the hydrogen intensity of $\mathrm{H}-2,2^{\prime}$ and $\mathrm{H}-9 \mathrm{a}, 9^{\prime} \mathrm{a}$ in a ${ }^{1} \mathrm{H}$ NMR experiment.

2: $\mathrm{mp} 123-124^{\circ} \mathrm{C}$; $[\alpha]_{\mathrm{D}}^{25}+68.6^{\circ}\left(\mathrm{c} 0.18, \mathrm{CHCl}_{3}\right) ;{ }^{1} \mathrm{H}$ NMR $\left(800 \mathrm{MHz}, \mathrm{CDCl}_{3}\right)$ $\delta 3.05\left(2 \mathrm{H}, \mathrm{m}, \mathrm{H}-8,8^{\prime}\right), 3.87\left(2 \mathrm{H}\right.$, dd, $\left.J=3.7,9.2 \mathrm{~Hz}, \mathrm{H}-9 \mathrm{a}, 9^{\prime} \mathrm{a}\right), 4.23(2 \mathrm{H}$, dd, $J=$ 6.7, 9.2 Hz, H-9b, 9'b), 4.71 ( $\left.2 \mathrm{H}, \mathrm{d}, J=4.2 \mathrm{~Hz}, \mathrm{H}-7,7^{\prime}\right), 5.95$ (4 H, s, H-10, 10'), $6.78\left(2 \mathrm{H}, \mathrm{d}, J=8.0 \mathrm{~Hz}, \mathrm{H}-5,5^{\prime}\right), 6.80\left(2 \mathrm{H}, \mathrm{br} \mathrm{d}, J=8.0 \mathrm{~Hz}, \mathrm{H}-6,6^{\prime}\right), 6.85(2 \mathrm{H}, \mathrm{br}$ d, $\left.J=1.6 \mathrm{~Hz}, \mathrm{H}-2,2^{\prime}\right) ;{ }^{13} \mathrm{C} \mathrm{NMR}\left(200 \mathrm{MHz}, \mathrm{CDCl}_{3}\right) \delta 54.3\left(\mathrm{C}-8,8^{\prime}\right), 71.6\left(\mathrm{C}-9,9^{\prime}\right)$, 85.70, $85.73\left(\mathrm{C}-7,7^{\prime}\right), 101.0\left(\mathrm{C}-10,10^{\prime}\right), 106.2\left(\mathrm{t}, J=24.8 \mathrm{~Hz}, \mathrm{C}-2,2^{\prime}\right), 106.4(\mathrm{C}-2$, $\left.2^{\prime}\right), 108.1\left(\mathrm{C}-5,5^{\prime}\right), 119.3\left(\mathrm{C}-6,6^{\prime}\right), 134.9,135.0\left(\mathrm{C}-1,1^{\prime}\right), 147.05,147.06\left(\mathrm{C}-4,4^{\prime}\right)$, $147.85,147.91\left(\mathrm{C}-3,3^{\prime}\right)$; HRMS (ESI): $[\mathrm{M}+\mathrm{Na}]^{+}$calculated for $\mathrm{C}_{20} \mathrm{H}_{16} \mathrm{D}_{2} \mathrm{O}_{6} \mathrm{Na}: \mathrm{m} / z$ 379.3549, found: 379.3540 . NMR spectra of 2 are shown in Supplementary Figs. 16-18.

LC-MS analysis of stable isotope labeled compounds. High-resolution mass spectra of all products including deuterated or ${ }^{18} \mathrm{O}$-labeled compounds were obtained using an ion-trap time-of-flight mass spectrometer (Shimadzu LCMS-ITTOF). A YMC-Triart C18 $(100 \times 2.1 \mathrm{~mm}, 3.0 \mu \mathrm{m})$ column was used for separation of enzymatic products derived from $(+)$-sesamin or deuterated $(+)$-sesamin. The mobile phase consisted of $0.1 \%$ formic acid in MilliQ water (A) and $0.1 \%$ formic acid in methanol (B) and used for a linear gradient elution (0-7-10-10.01-15 min, 30-90-90-30-30\%B). Positive and negative ions were measured simultaneously. The parameters were as follows: nebulizer gas, $1.5 \mathrm{~L} / \mathrm{min}$; drying gas pressure, 190 $\mathrm{kPa}$; CDL temperature, $200{ }^{\circ} \mathrm{C}$; block heater temperature, $200{ }^{\circ} \mathrm{C}$; detector, $1.64 \mathrm{kV}$; and interface, $4.5 \mathrm{kV}$ (positive mode) and $-3.5 \mathrm{kV}$ (negative mode).

NMR analysis of stable isotope labeled compounds. All NMR spectra of all products including deuterated compounds were acquired on a Bruker AVANCE III HD 800 spectrometer equipped with a 5 -mm TCI cryogenic probe and $Z$-axis gradient (Bruker Biospin). All spectra were measured at $25^{\circ} \mathrm{C}$, using $5 \mathrm{~mm} \mathrm{NMR}$ tubes. Standard Bruker pulse sequences were employed. The data analyses were 
carried out with Bruker TopSpin 3.2 software (Bruker Biospin). The acquisition parameters were as follows: ${ }^{1} \mathrm{H}$ NMR: number of data points $64 \mathrm{~K}$; spectral width $16025 \mathrm{~Hz}$; relaxation delay $10 \mathrm{~s}$; number of scans 64 ; receiver gain $3.2 ;{ }^{13} \mathrm{C}$ NMR: number of data points $64 \mathrm{~K}$; spectral width $48077 \mathrm{~Hz}$; relaxation delay $2 \mathrm{~s}$; number of scans 1024; receiver gain $203 ;{ }^{2} \mathrm{H}$ NMR: number of data points $64 \mathrm{~K}$; spectral width $4092 \mathrm{~Hz}$; relaxation delay $1 \mathrm{~s}$; number of scans 1024; receiver gain 128 . Chemical shift was reported in parts per million (p.p.m.) relative to the peaks from chloroform- $d\left(\mathrm{CDCl}_{3}, \delta_{\mathrm{H}} 7.26\right.$ p.p.m., $\delta_{\mathrm{C}} 77.0$ p.p.m.). The data for ${ }^{1} \mathrm{H}$ NMR are reported as follows: chemical shift, multiplicity $(s=$ singlet, $d=$ doublet, $t=$ triplet, $\mathrm{q}=$ quartet, $\mathrm{m}=$ multiplet), integration and coupling constants

RNA-seq. Total RNA was extracted from six developmental stages of seeds and germinating seeds (3 days after imbibition) using RNeasy Plant Kit (Qiagen). The developmental stages of sesame seeds were described previously ${ }^{10}$. The RNA samples were treated with DNase Set (Qiagen) to remove contaminating genomic DNA. The quality of each RNA sample was evaluated using BioAnalyzer (Agilent Technologies) with RNA6000 Nano Chip. A $1 \mathrm{mg}$ aliquot of total RNA from each sample was used to construct cDNA libraries using TruSeq Stranded Total RNA with Ribo-Zero Plant (Illumina) according to the manufacturer's instructions. The resulting cDNA library was validated using BioAnalyzer with DNA1000 Chip and quantified using Cycleave PCR Quantification Kit (TAKARA). Paired-end sequencing using $2 \times 101$ cycles was performed using HiSeq 1500 sequencing system (Illumina) in the high output mode.

Total reads were extracted using CASAVA v1.8.2 (Illumina), then PCR duplicates, adaptor sequences, and low quality reads were removed from the extracted reads as follows. Briefly, if the first 10 bases of two reads were identical and the entire reads showed $>90 \%$ similarity, the reads were considered to be PCR duplicates. Base calling from the $5^{\prime}$ to the $3^{\prime}$ end was stopped when the frequency of accurately called bases dropped to 0.5 . The remaining reads were assembled using Trinity ( 25 February 2013 release) by normalization with maximum coverage to 30 . For each sample, the Fragments per Kilobase Megareads (FPKM) values were calculated for contigs containing cDNA sequences responsible for CYP92B14, CYP81Q1, and CPR1 using Bowtie.

qPCR analysis. qPCR analysis was performed as described previously ${ }^{52}$. Briefly, $18 \mathrm{~S}$ rRNA was used as a reference gene for normalization and presented as expression ratios relative to control via the $\Delta \Delta \mathrm{Ct}$ method. Oligonucleotides used for the analysis are listed in Supplementary Table 3.

Enzyme assays using sesame microsome fractions. Fresh immature seeds ( $1 \mathrm{~g})$ in Stage 4 were frozen in liquid nitrogen and homogenized to a fine powder under liquid nitrogen cooling using TissueLyzer II (Qiagen), then resuspended in $2 \mathrm{ml}$ of extraction buffer I containing $100 \mathrm{mM}$ Tris- $\mathrm{Cl}(\mathrm{pH}$ 8.0), $0.1 \% \beta$-mercaptoethanol, $1 \times$ Complete EDTA-free protease inhibitor (Roche) and $20 \%$ glycerol. The homogenate was desalted using a MicroSpin HR S-400 column (GE Healthcare) and centrifuged at $21,000 \times g$ for $10 \mathrm{~min}$ at $4^{\circ} \mathrm{C}$, then the supernatant was ultracentrifuged at $70,000 \times g$ for $1 \mathrm{~h}$ at $4^{\circ} \mathrm{C}$. The pellet was resuspended in $200 \mu \mathrm{l}$ of Extraction buffer I. The microsome fraction $(10 \mu \mathrm{l})$ was mixed with $100 \mu \mathrm{M}$ (+)-sesamin and $1 \mathrm{mM}$ NADPH in a final volume of $50 \mu \mathrm{l}$ and incubated for $30 \mathrm{~min}$ at $37^{\circ} \mathrm{C}$. Heat inactivation was conducted by incubating the microsome fraction at $96^{\circ} \mathrm{C}$ for $5 \mathrm{~min}$ prior to the enzyme assay. The reaction was terminated by the addition of an equal volume of acetonitrile, the reaction mixture was filtered through a Millex-LH syringe filter (Merck Millipore), then analyzed either by using an HPLC equipped with a photodiode array detector (Waters) ${ }^{53}$ or an LC-MS equipped with a fluorescent detector (Shimadzu), unless otherwise stated.

Plasmid construction and yeast transformation. cDNAs of CYP92B14, Del4C, CPR1, and CYP81Q1 were amplified with cDNAs derived from sesame seeds at developmental stage 4 as the PCR templates and specific primer sets, described in Supplementary Table 3. Amplified fragments were inserted into the yeast expression vectors pYE22m, pDEST52 (Invitrogen), and pJHXSBP-His using standard procedures. The plasmid list and vector information are shown in Supplementary Table 3. Individual genes cloned in each vector were verified by DNA sequencing of both strands. Yeast INVsc strain (Invitrogen) was transformed using a conventional method with yeast expression vectors carrying Sesamum genes. The transformed yeast colonies were isolated on SD agar plates without selection compounds for 2 days at $30^{\circ} \mathrm{C}$.

Enzyme assays using yeast microsome fractions. Yeast cell lines expressing CYP92B14 and CPR1, Del4C and CPR1, CYP92B14 alone or CPR1 alone were precultured in $50 \mathrm{ml} \mathrm{SD}$ medium lacking respective amino acids overnight at $120 \mathrm{r}$. p.m. $30^{\circ} \mathrm{C}$. The saturated culture was transferred to $950 \mathrm{ml} \mathrm{SD}$ liquid medium without respective amino acids and cultured at 120 r.p.m. $30^{\circ} \mathrm{C}$ until the $\mathrm{OD}_{600}$ reached 2.0. The cells were harvested by centrifugation at $10,000 \times g$ for $15 \mathrm{~min}$ at $4^{\circ}$ C. The pellet was rinsed once and resuspended in $10 \mathrm{ml}$ of Extraction buffer I, followed by sonication at $4^{\circ} \mathrm{C}$. The homogenate was centrifuged at $21,000 \times g$ for 10 min at $4{ }^{\circ} \mathrm{C}$, then the supernatant was ultracentrifuged at $70,000 \times g$ for $1 \mathrm{~h}$ at $4^{\circ} \mathrm{C}$. The pellet was resuspended in $600 \mu \mathrm{l}$ of extraction buffer I and subjected to enzyme assays. The microsome fraction $(50 \mu \mathrm{l})$ was mixed with $100 \mu \mathrm{M}(+)$-sesamin and 1
mM NADPH in a final volume of $100 \mu \mathrm{l}$ and incubated for $60 \mathrm{~min}$ at $37^{\circ} \mathrm{C}$. The reaction was terminated by the addition of an equal volume of acetonitrile, and the mixture was filtered through a Millex-LH syringe filter (Merck Millipore), then subjected to HPLC analysis.

Bioassay experiments in yeast cells. For $1 \mathrm{ml}$-scale experiments, single colonies of yeast strains expressing the ORF sets CYP92B14+CPR1 or Del4C+CPR1 were cultured in $3 \mathrm{ml}$ synthetic defined liquid medium overnight at $30^{\circ} \mathrm{C}$ with rotary shaking at 120 r.p.m. The stationary phase culture $(50 \mu \mathrm{l})$ was transferred to $1 \mathrm{ml}$ of fresh medium in 24-well plates supplemented with $100 \mu \mathrm{M}$ of the lignan being tested as a substrate in the experiment. The cultures were further incubated for $24 \mathrm{~h}$ unless otherwise stated at $30^{\circ} \mathrm{C}$ with rotary shaking at 120 r.p.m. The efficiency of lignan extraction from the culture by the addition of an equal volume of acetonitrile was verified (Supplementary Fig. 19). Briefly, the cells were collected together with the medium and disrupted by sonication. The homogenate $(50 \mu \mathrm{l})$ was mixed with $50 \mu \mathrm{l}$ acetonitrile and centrifuged at $21,000 \times \mathrm{g}$ for $10 \mathrm{~min}$. The supernatant was filtered through a Millex-LH syringe filter and subjected to LC-MS analysis. The identity of the reaction products was confirmed by comparing the retention time and parent mass with authentic lignan standards.

For the ${ }^{2} \mathrm{H}$-labeling studies, yeast cells carrying CYP92B14+CPR1 were cultured in $600 \mathrm{ml}$ of liquid medium containing $200 \mu \mathrm{M}$ of ${ }^{2} \mathrm{H}$-labeled sesamin for $48 \mathrm{~h}$ at $30^{\circ} \mathrm{C}$ with rotary shaking at 120 r.p.m., then extracted twice with an equal volume of ethyl acetate. The organic layer was dehydrated with magnesium sulfate, dried in vacuo to dryness, and reconstituted with $400 \mu \mathrm{l}$ of $50 \%$ acetonitrile. The extract was fractionated by HPLC, and the fractions containing enzyme reaction products were subjected to MS and NMR analyses. NMR spectra of enzyme reaction products are shown in Supplementary Figs. 20-23.

For the ${ }^{18} \mathrm{O}$-labeling studies, either yeast medium prepared with ${ }^{18} \mathrm{O}$-labeled $\mathrm{H}_{2} \mathrm{O}$ (Taiyo Nippon Sanso), or yeast medium prepared with non-labeled $\mathrm{H}_{2} \mathrm{O}$ and aerated with ${ }^{18} \mathrm{O}$-labeled $\mathrm{O}_{2}$ (GL Science), was used for the yeast bioassay experiments. Briefly, the cells were cultured in $1 \mathrm{ml}$ of ${ }^{18} \mathrm{O}$-labeled medium containing $100 \mu \mathrm{M}$ sesamin in 24 -well plates for $48 \mathrm{~h}$ at $30^{\circ} \mathrm{C}$ with rotary shaking at 120 r.p.m. Alternatively, $50 \mu \mathrm{l}$ of stationary phase liquid cultures of yeast cells were sub-cultured in $1 \mathrm{ml}$ of non-labeled liquid medium bubbled in advance with ${ }^{18} \mathrm{O}$-labeled $\mathrm{O}_{2}$ at a rate of $1 \mathrm{ml} / \mathrm{min}$ for $10 \mathrm{~min}$. The air space in the test tubes was replaced with ${ }^{18} \mathrm{O}$-labeled $\mathrm{O}_{2}$, then the tubes were sealed tightly and the yeast cells were cultured for $4 \mathrm{~h}$ at $30^{\circ} \mathrm{C}$ with rotary shaking at 120 r.p.m. The reactions were terminated by the addition of an equal volume of acetonitrile, filtered through a Millex-LH filter, and analyzed by LC-MS.

CO-difference spectroscopy. Yeast cells expressing the ORF sets CYP92B14 + CPR1 or Del4C+CPR1 were cultured in two three liter flasks containing one liter medium to an $\mathrm{OD}_{600}$ of 2.0. The cells were collected by centrifugation at $10,000 \times g$ for $15 \mathrm{~min}$ at $4{ }^{\circ} \mathrm{C}$ and rinsed once with $50 \mathrm{ml}$ of distilled water. The cells were resuspended in extraction buffer I, disrupted by sonication on ice, then the homogenate was centrifuged at $10,000 \times g$ for $15 \mathrm{~min}$ at $4{ }^{\circ} \mathrm{C}$, followed by ultracentrifugation at $75,000 \times g$ for $1 \mathrm{~h}$ at $4^{\circ} \mathrm{C}$. The pellet was resuspended in $600 \mu \mathrm{l}$ of extraction buffer. CO-difference spectroscopy was conducted basically as described previously ${ }^{54}$. Briefly, the absorbance spectrum $(400-500 \mathrm{~nm})$ of the obtained microsome fraction was measured, then the microsome fraction was reduced by the addition of sodium dithionite and the spectrum of the reduced form was measured. The microsome fraction was then saturated with $\mathrm{CO}$ by bubbling $\mathrm{CO}$ for $1 \mathrm{~min}$ and the spectrum of the CO-bound form of P450 monooxygenase was measured.

Immunoblot analysis. Microsomal proteins of yeast cells expressing CPR1 with either CYP92B14 or Del4C were separated by SDS-PAGE and subjected to immunoblot analysis. Briefly, $20 \mu \mathrm{g}$ of microsomal proteins per lane was separated by SDS-PAGE using a 5-20\% acrylamide gradient gel and blotted onto a Hybond-P VDF membrane (GE Healthcare). Primary antibody reactions used $500 \times$ diluted rabbit polyclonal antibodies raised against a 1:1 mixture of the oligopeptides $\mathrm{NH}_{2-}$ C+WRQARKIYLSEVF-COOH and $\mathrm{NH}_{2}-\mathrm{C}+\mathrm{QFLRLHDKVFASRP-COOH}$ (Eurofins Genomics), both of which are perfectly conserved among all the P450 monooxygenases analyzed in the immunoblot analysis. Secondary antibody reactions used 5000× diluted rabbit IgG-HRP (GE Healthcare). Chemiluminescent detection was performed using ECL Select (GE Healthcare) as a substrate with Amersham Imager 600 (GE Healthcare) (Supplementary Fig. 5).

Data availability. The authors declare that fastq files for RNASeq data have been deposited in the NCBI SRA repository under Accession ID PRJNA350858. Sequences for CYP92B14 and CPR1 have been deposited in GenBank under accession codes LC199944 and LC209223, respectively. The authors declare that all other data supporting the findings of this study are available within the manuscript and its Supplementary Files or are available from the corresponding author upon request.

Received: 28 March 2017 Accepted: 2 November 2017

Published online: 18 December 2017 


\section{References}

1. Bedigian, D. \& Harlan, J. R. Evidence for cultivation of sesame in the ancient world. Econ. Bot. 40, 137-154 (1986).

2. Umezawa, T. Diversity in lignan biosynthesis. Phytochem. Rev. 2, 371-390 (2003).

3. Davin, L. B. \& Lewis, N. G. An historical perspective on lignan biosynthesis: Monolignol, allylphenol and hydroxycinnamic acid coupling and downstream metabolism. Phytochem. Rev. 2, 257-288 (2003).

4. Liu, Z., Saarinen, N. M. \& Thompson, L. U. Sesamin is one of the major precursors of mammalian lignans in sesame seed (Sesamum indicum) as observed in vitro and in rats. J. Nutr. 136, 906-912 (2006).

5. Katayama, S. et al. Effects of sesaminol feeding on brain $A \beta$ accumulation in a senescence-accelerated mouse-prone 8. J. Agric. Food Chem. 64, 4908-4913 (2016).

6. Baek, S. \& Lee, S. Sesamol decreases melanin biosynthesis in melanocyte cells and zebrafish: possible involvement of MITF via the intracellular cAMP and p38/JNK signalling pathways. Exp. Dermatol. 24, 761-766 (2015).

7. Prasad, N. R., Mahesh, T., Menon, V. P., Jeevanram, R. K. \& Pugalendi, K. V. Photoprotective effect of sesamol on UVB-radiation induced oxidative stress in human blood lymphocytes in vitro. Environ. Toxicol. Pharmacol. 20, 1-5 (2005).

8. Yamauchi, S., Ichikawa, H., Nishiwaki, H. \& Shuto, Y. Evaluation of plant growth regulatory activity of furofuran lignan bearing a 7,9':7',9-diepoxy structure using optically pure (+)- and (-)-enantiomers. J. Agric. Food Chem. 63, 5224-5228 (2015)

9. Davin, L. B. et al. Stereoselective bimolecular phenoxy radical coupling by an auxiliary (dirigent) protein without an active center. Science 275, 362-366 (1997)

10. Ono, E. et al. Formation of two methylenedioxy bridges by a Sesamum CYP81Q protein yielding a furofuran lignan, (+)-sesamin. Proc. Natl Acad. Sci. USA 103, 10116-10121 (2006).

11. Ghosal, H., Banerjee, S. \& Srivastava, S. Simplexolin, A new lignan from Justicia simplex. Phytochemistry 18, 503-505 (1979).

12. Zhu, H., Zhao, D., Deng, J. \& Zhang, Y. Two new lignans from Phryma leptostachya L. Helv. Chem. Acta 96, 1392-1396 (2013).

13. Ide, $T$. et al. Comparative effects of sesame seeds differing in lignan contents and composition on fatty acid oxidation in rat liver. J. Oleo. Sci. 64, 211-222 (2015).

14. Etter, P. D., Bassham, S., Hohenlohe, P. A., Johnson, E. A. \& Cresko, W. A. SNP discovery and genotyping for evolutionary genetics using RAD sequencing. Methods Mol. Biol. 772, 157-178 (2011).

15. Wang, L. et al. Genome sequencing of the high oil crop sesame provides insight into oil biosynthesis. Genome Biol. 15, R39 (2014).

16. Nelson, D. R. The cytochrome p450 homepage. Hum. Genom. 4, 59-65 (2009).

17. Kang, J. G. et al. Light and brassinosteroid signals are integrated via a darkinduced small G protein in etiolated seedling growth. Cell 105, 625-636 (2001).

18. Singleton, C., Howard, T. P. \& Smirnoff, N. Synthetic metabolons for metabolic engineering. J. Exp. Bot. 65, 1947-1954 (2014).

19. Ohe, T., Mashino, T. \& Hirobe, M. Substituent elimination from p-substituted phenols by cytochrome P450 ipso-substitution by the oxygen atom of the active species. Drug Metab. Dispos. 25, 1-5 (1997).

20. Grougnet, R., Magiatis, P., Mitakou, S. \& Skaltsounis, A. in Sesame: the genus Sesamum (ed. Bedigian, D.) 93-110 (CRC Press, Florida, 2006).

21. Tomberg, A., Pottel, J., Liu, Z., Labute, P. \& Moitessier, N. Understanding P450-mediated bio-transformations into epoxide and phenolicmetabolites. Angew. Chemie-Int. Ed. 54, 13743-13747 (2015).

22. Ming, D. S., Yu, D. Q. \& Yu, S. S. New quinoid glycosides from Forsythia suspensa. J. Nat. Prod. 61, 377-379 (1998).

23. Tanaka, H., Tanaka, T. \& Etoh, H. A pterocarpan from Erythrina orientali. Phytochemistry 42, 1473-1475 (1996).

24. Saito, Y. et al. Chemical and genetic diversity of Ligularia virgaurea collected in northern Sichuan and adjacent areas of China. Isolation of 13 new compounds. Tetrahedron 68, 10011-10029 (2012).

25. Wada, H., Fujita, H., Murakami, T., Saiki, Y. \& Chen, C.-M. Chemical and chemotaxonomical studies of ferns. LXXIII. New flavonoids with modified BRing from the genus Pseudophegopteris (Thelypteridaceae). Chem. Pharm. Bull. 35, 4757-4762 (1987).

26. Lin, A. S., Chang, F. R., Wu, C. C., Liaw, C. C. \& Wu, Y. C. New cytotoxic flavonoids from Thelypteris torresiana. Planta. Med. 71, 867-870 (2005).

27. Liao, S. G. et al. Identification and characterisation of phenolics in polygonum capitatum by ultrahigh-performance liquid chromatography with photodiode array detection and tandem mass spectrometry. Phytochem. Anal. 24, 556-568 (2013).

28. Tang, Y. et al. Potential therapeutic agents for circulatory diseases from Bauhinia glauca Benth.subsp. pernervosa. (Da Ye Guan Men). Bioorg. Med. Chem. Lett. 25, 3217-3220 (2015).
29. Jo, Y. H. et al. Benzylated and prenylated flavonoids from the root barks of Cudrania tricuspidata with pancreatic lipase inhibitory activity. Bioorganic Med. Chem. Lett. 25, 3455-3457 (2015).

30. Panthong, K. et al. Two new triterpenes and a new coumaroyl glucoside from the twigs of Mangifera foetida Lour. Phytochem. Lett. 11, 43-48 (2015).

31. Tanaka, T., Watarumi, S., Matsuo, Y., Kamei, M. \& Kouno, I. Production of theasinensins $\mathrm{A}$ and $\mathrm{D}$, epigallocatechin gallate dimers of black tea, by oxidation-reduction dismutation of dehydrotheasinensin A. Tetrahedron 59, 7939-7947 (2003).

32. Leu, Y. L., Kuo, S. M., Hwang, T. L. \& Chiu, S. T. The inhibition of superoxide anion generation by neutrophils from Viscum articulactum. Chem. Pharm. Bull. 52, 858-860 (2004).

33. Vanholme, R., Demedts, B., Morreel, K., Ralph, J. \& Boerjan, W. Lignin biosynthesis and structure. Plant Physiol. 153, 895-905 (2010).

34. Bugg, T. D. H., Ahmad, M., Hardiman, E. M. \& Singh, R. The emerging role for bacteria in lignin degradation and bio-product formation. Curr. Opin. Biotechnol. 22, 394-400 (2011).

35. Johnson, E. F. \& Stout, C. D. Structural diversity of eukaryotic membrane cytochrome P450s. J. Biol. Chem. 288, 17082-17092 (2013).

36. Sawada, N., Sakaki, T., Kitanaka, S., Kato, S. \& Inouye, K. Structure-function analysis of CYP27B1 and CYP27A1. Eur. J. Biochem. 268, 6607-6615 (2001).

37. Fukuda, Y., Isobe, M., Nagata, M., Osawa, T. \& Namiki, M. Acidic transformation of sesamolin, the sesame-oil constituent, into an antioxidant bisepoxylignan, sesaminol. Heterocycles 24, 923-926 (1986).

38. Marchand, P. A., Zajicek, J. \& Lewis, N. G. Oxygen insertion in Sesamum indicum furanofuran lignans. Diastereoselective syntheses of enzyme substrate analogues. Can. J. Chem. 75, 840-849 (1997)

39. Noguchi, A. et al. Mode-of-action and evolution of methylenedioxy bridge forming P450s in plant specialized metabolism. Plant Biotechnol. 31, 493-503 (2014).

40. Bedigian, D., Seigler, D. S. \& Harlan, J. R. Sesamin, sesamolin and the origin of sesame. Biochem. Syst. Ecol. 13, 133-139 (1985).

41. Laursen, T., Møller, B. L. \& Bassard, J. E. Plasticity of specialized metabolism as mediated by dynamic metabolons. Trends Plant Sci 20, 20-32 (2015).

42. Bulutoglu, B. et al Direct evidence for Metabolon Formation and Substrate Channeling in Recombinant TCA Cycle Enzymes. ACS Chem. Biol. 11, 2847-2853 (2016).

43. Laursen, T. et al. Characterization of a dynamic metabolon producing the defense compound dhurrin in sorghum. Science 354, 890-893 (2016).

44. Waki, T. et al. Identification of protein-protein interactions of isoflavonoid biosynthetic enzymes with 2-hydroxyisoflavanone synthase in soybean (Glycine $\max ($ L.) Merr.). Biochem. Biophys. Res. Commun. 469, 546-551 (2016).

45. Kawamura, K. et al. Genetic distance of inbred lines of Chinese cabbage and its relationship to heterosis. Plant Gene 5, 1-7 (2016).

46. Neff, M. M., Neff, J. D., Chory, J. \& Pepper, A. E. dCAPS, a simple technique for the genetic analysis of single nucleotide polymorphisms: experimental applications inArabidopsis thaliana genetics. Plant J. 14, 387 (1998).

47. Iwata, H. \& Ninomiya, S. AntMap: constructing genetic linkage maps using an ant colony optimization algorithm. Breed Sci. 56, 371-377 (2006).

48. Wei, L., Miao, H., Zhao, R., Han, X. \& Zhang, T. Identification and testing of reference genes for Sesame gene expression analysis by quantitative real-time PCR. Planta 237, 873-889 (2013).

49. Kumar, S., Stecher, G. \& Tamura, K. MEGA7: molecular evolutionary genetics analysis version 7.0 for bigger datasets. Mol. Biol. Evol. 33, 1870-1874 (2016)

50. Kurita, T. et al. Efficient and convenient heterogeneous palladium-catalyzed regioselective deuteration at the benzylic position. Chem.-A Eur. J. 14, 664-673 (2008).

51. Kato, M. J., Chu, A., Davin, L. B. \& Lewis, N. G. Biosynthesis of antioxidant lignans in Sesamum indicum seeds. Phytochemistry 47, 583-591 (1998).

52. Noguchi, A. et al. Sequential glucosylation of a furofuran lignan, (+)-sesaminol, by Sesamum indicum UGT71A9 and UGT94D1 glucosyltransferases. Plant J. 54, 415-427 (2008).

53. Kim, H. J. et al. Metabolic engineering of lignan biosynthesis in forsythia cell culture. Plant Cell Physiol. 50, 2200-2209 (2009).

54. Omura, T. \& Sato, R. The Carbon Monoxide-biding pigment of Liver Microsomes. J. Biol. Chem. 239, 2370-2378 (1964).

\section{Acknowledgments}

We thank T. Amano and T. Kondo for ITCFA2002 seeds, and NARO for Maruemon seeds. We are also grateful to K. Namba, T. Sakaki, T. Umezawa, T. Waki, S. Takahashi, T. Nakayama, H. Takagi, H. Satake, K. Shimamoto, S. Nakanishi, H. Hatanaka, M. Fukuchi-Mizutani, M. Nakai, Y. Ono, and K. Yamada for fruitful discussion. This research was supported partly by JST PRESTO JP16H01473 (A.J.N.) and Grants-in-Aid for Scientific Research (C) JP25450003 (M.P.Y.). 


\section{Author contributions}

M.P.Y. and M.H. designed the research, S.Y., T.W., and M.P.Y. performed genetic analyses, E.O. and H.T. cloned CYP92B14, A.J.N. conducted RAD-Seq analyses, E.O. and A.S. analyzed RNA-Seq data, J.M. and M.H. performed biochemical analyses, M.N. and M.M. performed CO-difference spectra analysis, M.H., M.T., and T.A. conducted chemical syntheses, M.H. and S.M. performed NMR analyses, and J.M., E.O., M.P.Y., and M. H. wrote the manuscript. J.M., E.O., and S.Y. contributed equally to this work.

\section{Additional information}

Supplementary Information accompanies this paper at https://doi.org/10.1038/s41467017-02053-7.

Competing interests: E.O. and H.T. are employees of Suntory Global Innovation Center, Ltd. Suntory Foundation for Life Sciences is a non-profit organization. The corresponding authors had full access to all the data in the study and had final responsibility for the decision to submit for publication. All other authors declare no competing financial interests.

Reprints and permission information is available online at http://npg.nature.com/ reprintsandpermissions/
Publisher's note: Springer Nature remains neutral with regard to jurisdictional claims in published maps and institutional affiliations.

(c) (i) Open Access This article is licensed under a Creative Commons Attribution 4.0 International License, which permits use, sharing, adaptation, distribution and reproduction in any medium or format, as long as you give appropriate credit to the original author(s) and the source, provide a link to the Creative Commons license, and indicate if changes were made. The images or other third party material in this article are included in the article's Creative Commons license, unless indicated otherwise in a credit line to the material. If material is not included in the article's Creative Commons license and your intended use is not permitted by statutory regulation or exceeds the permitted use, you will need to obtain permission directly from the copyright holder. To view a copy of this license, visit http://creativecommons.org/ licenses/by/4.0/.

(C) The Author(s) 2017 